\title{
Impacts of grazing and mowing on reproductive behaviors of Stipa grandis and Stipa krylovii in a semi-arid area
}

\author{
Hui GAO, YuBao GAO*, XingDong HE \\ College of Life Sciences, Nankai University, Tianjin 300071, China
}

\begin{abstract}
Disturbance can affect biomass allocation of plants, but can it influence plant reproductive behavior? To address this issue, we performed field plant community investigations and explored the reproductive behaviors of Stipa grandis and Stipa krylovii in response to grazing and mowing treatments at Maodeng pasture of Xilinguole League of Inner Mongolia, China during 2007-2009. The results showed that, with a similar niche width for the two plant species under mowing and grazing treatments, mowing significantly increased the ratio of ramet to genet number of $S$. krylovii and the carbon to nitrogen ratio of $S$. grandis, and grazing significantly decreased the ratio of vegetative to reproductive tiller biomass of $S$. grandis and increased the ratio of vegetative to reproductive tiller number of $S$. krylovii. Regression analysis showed that the significantly positive effect of root to shoot biomass ratio was stronger on the ratio of vegetative to reproductive tiller number of $S$. grandis than on that of $S$. krylovii. These results indicated that grazing and mowing influenced the reproductive manner and the process of sexual reproduction of S. grandis and S. krylovii.
\end{abstract}

Keywords: Stipa grandis; Stipa krylovii; disturbance; Maodeng pasture; reproductive strategy

Citation: Hui GAO, YuBao GAO, XingDong HE. 2014. Impacts of grazing and mowing on reproductive behaviors of Stipa grandis and Stipa krylovii in a semi-arid area. Journal of Arid Land, 6(1): 97-104. doi: 10.1007/s40333-013-0196-5

Disturbance is an important factor that influences plant growth and vegetation dynamic process (Grime, 2001). In disturbed conditions, plant traits can undergo strong environmental selective pressures (Harper, 1977; Denslow, 1980; Miao and Bazzaz, 1990; McIntyre et al., 1995). Disturbance makes plants difficult to reach an optimal resource allocation, as vegetative life-history characteristics restrain one another. To adapt to disturbance, plants adjust resource allocation and make life-history traits reach an optimization through trade-offs (Reznick, 1985; Obeso, 2002).

As for the reproductive behavior of plants, disturbance can change sprouting ability of plants (Weiher et al., 1999). Under circumstances of wind-sand, the vegetative reproduction ability of plants is subject to their strengths of resisting wind erosion and sand bur- ial (Liu et al., 1999). After forest fire, felling and floods, the vegetative reproduction ability of plants is also readily enhanced (Chen and Song, 1997; Del Barrio et al., 1999; Pausas, 1999). However, how grazing and mowing affect the reproductive manner and the process of sexual reproduction of plants remains an issue to be explored.

Grazing and mowing, as common disturbances in grassland, usually affect the biomass distribution between plant growth and reproduction (Adler et al., 2001; Begay et al., 2011; Guo et al., 2011; N'Guessan and Hartnett, 2011; Kioko et al., 2012). This phenomenon is mainly due to changed plant growth conditions caused by grazing and mowing, which affect not only the morphology and phenology (Van Tienderen and van der Toorn, 1991; Franks et al. 2007; Reisch and Poschlod, 2011) but also the resource al-

*Corresponding author: YuBao GAO (E-mail: ybgao@nankai.edu.cn) Received 2013-02-03; revised 2013-03-20; accepted 2013-05-21

(C) Xinjiang Institute of Ecology and Geography, Chinese Academy of Sciences, Science Press and Springer-Verlag Berlin Heidelberg 2013 
location manner of plants (Aoyagi and Akimoto, 2009; Mao et al., 2012) of different ecological types. The way in which plants allocate their resources is one of the most important factors in determining the persistence of plant growth (Mulder and Ruess, 1998; Taisma and Herrera, 1998; Wilkins, 2002), and could also affect plant reproductive behavior.

The reproductive behavior of plant species is critically restricted by internal (e.g. size and age) and external (e.g. temperature and light) aspects (De Jong et al., 1998). Whereas the onset of reproduction is often regulated by the individual size in short-lived monocarpic plants, and the reproductive behavior of perennial polycarpic plants depends on a complex interaction between the amount of resources currently used in reproduction and the amount of resources stored for future reproduction (Brys et al., 2011), because reproduction in one year may contribute to the survival, growth and reproduction in the next (Stearns, 1992). During the reproductive stage, therefore, monocarpic plant species have only one choice in response to grazing and mowing, and they must immediately repair the injury to compensate for the lost biomass and damaged reproductive structures; while polycarpic plant species have more options than monocarpic plants (Huhta et al., 2009). Brys et al. (2011) explored the impact of herbivores on the flowering behavior of long-lived polycarpic herbs, providing an important reference for our research. In the present study, we hypothesized that, in a semi-arid area, grazing and mowing could change reproductive behaviors in the perennial grasses Stipa grandis and Stipa krylovii. Our objective was to determine the reproductive behaviors of $S$. grandis and S. krylovii in response to disturbance.

\section{Materials and methods}

\subsection{Study area and plant species}

The study area was in the Maodeng pasture $\left(43^{\circ} 37^{\prime} 48^{\prime \prime}-44^{\circ} 15^{\prime} 00^{\prime \prime} \mathrm{N}, 116^{\circ} 23^{\prime} 24^{\prime \prime}-116^{\circ} 28^{\prime} 12^{\prime \prime} \mathrm{E}\right)$ located $50 \mathrm{~km}$ in the east of Xilinhot city, Xilinguole League, Inner Mongolia of China. This region has a typical semi-arid continental climate, with an annual mean air temperature of $1.7^{\circ} \mathrm{C}$, a mean annual precipitation of $287 \mathrm{~mm}$ and a mean annual evaporation of $1,746 \mathrm{~mm}$. The soil in the study area is Kastanozem, and the vegetation is a typical steppe. $S$. grandis and $S$. krylovii are both perennial tussock grasses and are dominant species in the typical steppe of the Inner Mongolian Plateau (Inner Mongolia-Ningxia Integrated Survey Team, 1985).

\subsection{Field sampling and measurement}

In the study area, three adjacent areas with grazing, mowing and unused treatments were selected. In each treatment area, both $S$. grandis and $S$. krylovii occurred. Cattle and sheep have been fed in the grazing area for several decades. The mowing area was fenced and established in 2004, and was mowed annually at the end of each growing season. The unused area represented natural grassland free of grazing and mowing. Within each treatment, two $50 \mathrm{~m} \times 50 \mathrm{~m}$ plots were set up and dominated by $S$. grandis and $S$. krylovii, respectively. We set up six plots totally for the three treatments. To investigate how reproductive behavior was affected by grazing and mowing, 10 quadrats of 1 $\mathrm{m} \times 1 \mathrm{~m}$ were randomly laid out within each plot in late August 2007 at full maturity of grasses and before the onset of senescence. We counted the total number of genets and the number of vegetative and reproductive tillers of each genet of $S$. grandis and S. krylovii within each respective quadrat. The biomass of vegetative and reproductive tillers was oven-dried separately at $80^{\circ} \mathrm{C}$ for $48 \mathrm{~h}$ and weighed. For determining the carbon $(\mathrm{C})$ and nitrogen $(\mathrm{N})$ contents of mature plants, mixed samples (vegetative and reproductive tillers) of each quadrat for each species were oven-dried and weighed before further chemical analysis. To investigate the relationship between reproductive behavior and above- and below-ground resource allocation, in each treatment, 30 individuals of $S$. grandis and S. krylovii were randomly sampled in late August 2008, respectively. Each individual of both species was divided into above- and below-ground parts; the numbers of vegetative and reproductive tillers were counted; and the biomass of each part was weighed after oven drying. Plant species compositions and their community features under grazing, mowing and unused treatments were investigated in late August 2009, by randomly laying out 10 
quadrats of $1 \mathrm{~m} \times 1 \mathrm{~m}$ within each plot, with a total of 60 quadrats. In each quadrat, we identified all species and measured their height, density and biomass. All biomass was weighed after oven drying to a constant weight at $80^{\circ} \mathrm{C}$.

For plant $\mathrm{C}$ and $\mathrm{N}$ measurements, the oven dried mixed sample of each plant was ground with a ball mill (Retsch MM 301L, Retsch GmbH and Co KG, Haan, Germany) and weighed, and then digested in $\mathrm{H}_{2} \mathrm{SO}_{4}-\mathrm{H}_{2} \mathrm{O}_{2}$. The $\mathrm{N}$ content was determined by Semimicro-Kjeldahl method, and the $\mathrm{C}$ content by potassium bichromate titrimetric method (Bao, 2000). Three replicates were performed for these measurements.

\subsection{Statistical analysis}

The importance value index (IVI) represents the relative importance of a species in a given community ( $\mathrm{He}$ et al., 2004). The IVI was defined as the sum of relative density, relative height and relative biomass. The niche width of $S$. grandis and S. krylovii was determined by Simpson-Yule index (Song, 2001; Liu et al., 2004): $B_{i}=Y_{i}^{2} \Sigma N_{i}^{2}$, where, $B_{i}$ is niche width of species $i$; $N_{i}$ is the relative height, relative density, relative biomass and IVI for species $i$, respectively; and $Y_{i}$ is the sum of these indices of species $i$.

To gain insights into several aspects of the reproductive behaviors of $S$. grandis and $S$. krylovii and how they were affected by grazing and mowing, we first calculated the ratio of ramet (all tillers) number relative to genet number at a quadrat level for each species and each treatment. Additionally, we calculated the ratio of vegetative to reproductive tiller number and the ratio of vegetative to reproductive tiller biomass. To investigate the relationship between plant resources allocation and reproductive behaviors, we calculated the $\mathrm{C}$ to $\mathrm{N}$ content ratios $(\mathrm{C}: \mathrm{N})$ and root to shoot biomass ratios of both plant species. One-way analyses of variance (ANOVAs) were used to determine whether each of these variables was significantly affected by the three treatments. Statistical analysis was applied after testing for homogeneity of variance: if equal variances were indicated, the group comparison was tested by the Least Significant Difference test; then, if no equal variance was indicated, Tamhane's
T2 was used. Independent $t$-tests were used to test whether the interspecific differences were significant for every variable. All analyses were carried out with SPSS version 13.0 (SPSS Inc., Chicago, IL, USA).

\section{Results}

\subsection{IVI and niche width}

There were 30 plant species belonging to 10 families and 24 genera in the three treatment areas. The dominant families were Gramineae, Leguminosae, Liliaceae and Rosaceae. The most dominant species for all three treatments areas were Cleistogenes sguarosa, Leymus chinensis, S. grandis, Agropyron cristatum and S. krylovii (Table 1). Although $S$. grandis had higher IVI than S. krylovii, the niche width of both species was similar (Table 2).

\subsection{Reproductive behavior}

The ratio of ramet to genet number of $S$. grandis showed no significant effect among the grazing, mowing and unused treatments $(F=0.475 ; P=0.624)$; however, there was a significant effect for $S$. krylovii $(F=4.182 ; P=0.020)$ (Fig. 1). The ratio of ramet to genet number of $S$. krylovii differed significantly between the mowing and unused treatments, but no significance was observed between the grazing and unused treatments. The effect of the three treatments was not significant for the ratio of vegetative to reproductive tiller number of $S$. grandis $(F=1.193 ; P=0.311)$, but was significant for $S$. krylovii $(F=3.953 ; P=0.025)$. For $S$. krylovii, there was a significant difference between the grazing and unused treatments, but no significant difference was found between the mowing and unused treatments. However, the ratio of vegetative to reproductive tiller number for $S$. grandis showed an increasing trend from grazing, mowing to unused treatments, with ratios of $28.13 \pm 5.76$, $38.19 \pm 10.23$ and $46.24 \pm 8.22$, respectively; however, for $S$. krylovii there was a decreasing trend with corresponding values of $5.08 \pm 1.90,2.73 \pm 0.55$ and $1.22 \pm 0.62$, respectively. For the ratio of vegetative to reproductive tiller biomass, there was a significant effect of the three treatments for $S$. grandis $(F=3.511$; $P=0.036)$, but not for $S$. krylovii $(F=1.758 ; P=0.182)$. 
Table 1 Plant species and importance value index (IVI) for the three treatments

\begin{tabular}{|c|c|c|c|c|c|c|c|}
\hline Species & Grazing & Mowing & Unused & Species & Grazing & Mowing & Unused \\
\hline Agropyron cristatum & 0.217 & 0.270 & 0.255 & Heteropappus altaicus & 0.044 & 0.021 & \\
\hline Allium anisopodium & 0.037 & 0.032 & 0.043 & Iris tenuifolia & 0.071 & 0.040 & 0.038 \\
\hline Allium macrostemum & & & 0.019 & Koeleria cristata & 0.019 & 0.026 & 0.032 \\
\hline Allium tenuissimum & 0.062 & 0.036 & 0.046 & Leymus chinensis & 0.792 & 0.571 & 0.691 \\
\hline Anemarrhena asphodeloides & 0.019 & 0.027 & & Melilotus suaveole & & 0.113 & \\
\hline Artemisia frigida & 0.053 & 0.110 & 0.118 & Melissitus ruthenicus & 0.036 & & \\
\hline Artemisia sieversiana & 0.051 & 0.053 & 0.025 & Oxytropis aciphylla & & & 0.074 \\
\hline Asparagus dauricus & & 0.031 & & Potentilla bifurca & 0.034 & & \\
\hline Astragalus galactites & 0.026 & 0.014 & 0.134 & Salsola collina & 0.051 & 0.014 & 0.031 \\
\hline Carex korshinskyi & 0.111 & 0.158 & 0.062 & Saposhnikovia divaricata & & 0.027 & \\
\hline Cleistogenes sguarosa & 0.639 & 0.682 & 0.627 & Scutellavia scordifolia & 0.043 & 0.078 & \\
\hline Cleistogenes songonia & & & 0.060 & Serratula spp. & 0.050 & 0.051 & 0.103 \\
\hline Cymbaria dahurica & & 0.041 & & Sibbaldia adpressa & 0.013 & 0.014 & \\
\hline Elymus dahuricus & 0.095 & & & Stipa grandis & 0.318 & 0.361 & 0.413 \\
\hline Heterobostrychus hamatipeunis & 0.036 & & 0.018 & Stipa krylovii & 0.181 & 0.230 & 0.213 \\
\hline
\end{tabular}

Table 2 Dominance and niche width of S. grandis and S. krylovii

\begin{tabular}{|c|c|c|c|c|c|c|}
\hline \multirow{2}{*}{ Index } & \multicolumn{2}{|c|}{ Grazing } & \multicolumn{2}{|c|}{ Mowing } & \multicolumn{2}{|c|}{ Unused } \\
\hline & S. grandis & S. krylovii & S. grandis & S. krylovii & S. grandis & S. krylovii \\
\hline Relative density & 0.058 & 0.031 & 0.056 & 0.012 & 0.057 & 0.022 \\
\hline Relative biomass & 0.168 & 0.060 & 0.213 & 0.052 & 0.253 & 0.053 \\
\hline Relative height & 0.092 & 0.090 & 0.093 & 0.165 & 0.103 & 0.138 \\
\hline Importance value index & 0.318 & 0.181 & 0.361 & 0.230 & 0.413 & 0.213 \\
\hline Niche width & 2.867 & 2.886 & 2.784 & 2.546 & 2.746 & 2.683 \\
\hline
\end{tabular}
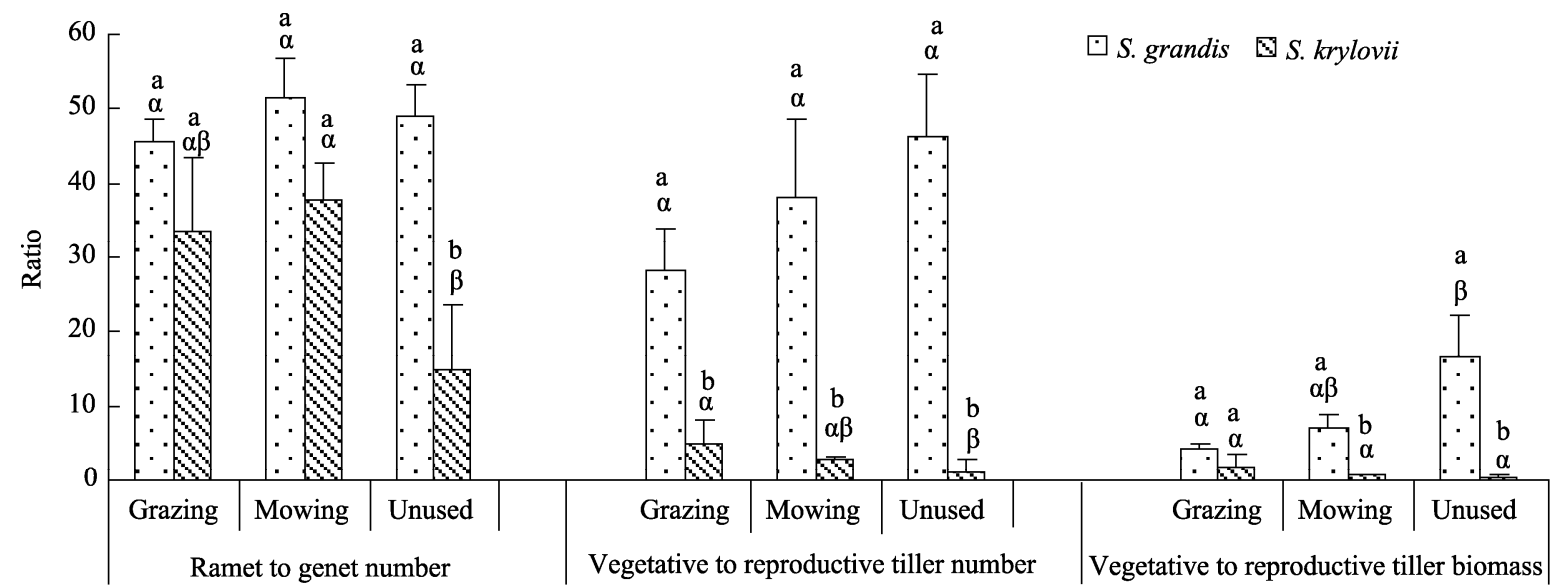

Fig. 1 Ratios of ramet to genet number, vegetative to reproductive tiller number and vegetative to reproductive tiller biomass for $S$. grandis and S. krylovii under three treatments. Significance for the three treatments is displayed with different latin letters according to one-way ANOVA, significance of differences between $S$. grandis and $S$. krylovii is displayed with lowercase letters tested by $t$-test $(p<0.05)$. Mean \pm SD.

In addition, the ratio of vegetative to reproductive tiller biomass of $S$. grandis differed significantly be- tween the grazing and unused treatments, but did not differ significantly between the mowing and unused 
treatments. For the grazing, mowing and unused treatments, the ratios of vegetative to reproductive tiller biomass for $S$. grandis and S. krylovii showed similar trends to the changes in the ratios of vegetative to reproductive tiller number.

\subsection{Relationship between resource allocation and reproductive behavior}

The C:N ratio of $S$. grandis was significantly higher for the mowing than for the grazing and unused treatments. The C:N ratio for $S$. krylovii showed no significant differences among the three treatments. There were significantly higher C:N ratios for $S$. krylovii than for $S$. grandis in the grazing treatment; however, the differences between the two species were not significant in the mowing and unused treatments (Fig. 2).

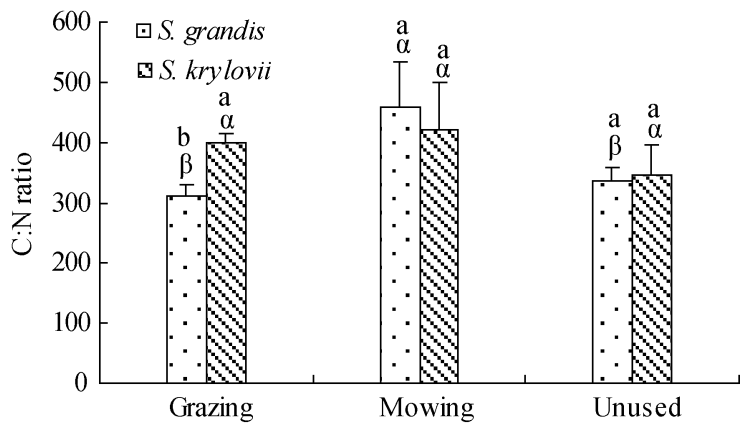

Fig. 2 C:N ratios of Stipa grandis and S. krylovii under three treatments. Significance representation is the same as for Fig. 1. Mean \pm SD.

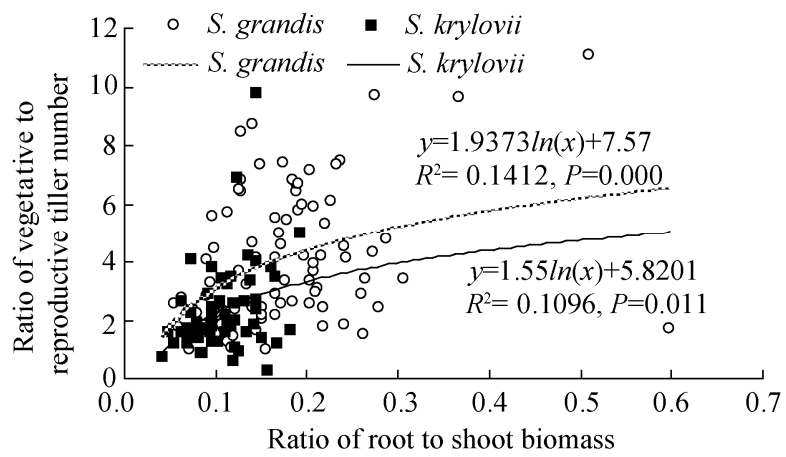

Fig. 3 The relationships between the ratios of vegetative to reproductive tiller number and the ratios of root to shoot biomass for Stipa grandis and S. krylovii

Regression analysis showed a significant positive logarithmic relationship between the ratios of vegetative to reproductive tiller number and the ratios of root to shoot biomass for both S. grandis and S. krylovii.
Moreover, the regression coefficient of $S$. grandis (1.9373) was greater than that of S. krylovii (1.55). Compared to $S$. krylovii, the root to shoot ratio of $S$. grandis had a greater effect on the ratio of vegetative to reproductive tiller number according to the regression coefficient (Fig. 3).

\section{Discussion}

Plant reproductive strategy in response to disturbance is an important theme in plant ecology (Grime, 2001). Ecologists are endeavoring to test the hypothesis of "whether plants, mainly through physiological characteristics, adapt to climate changes, or, through the reproductive characteristics, adapt to disturbances" (Liu et al., 2003; Liu, 2010). In this study, the ratios of ramet to genet number, vegetative to reproductive tiller number and vegetative to reproductive tiller biomass generally differed across the grazing, mowing and unused treatments for $S$. grandis and S. krylovii. The results provided an evidence of radical difference on reproductive behaviors between the two species under three treatments. The niche width of both species was similar for the three treatments. However, the grazing and mowing treatments had different influences on the reproductive behaviors of $S$. grandis and S. krylovii. The mowing treatment significantly affected the ratio of ramet to genet number for S. krylovii, but had no significant effect for $S$. grandis. Due to the greater dominance of $S$. grandis relative to $S$. krylovii in the study area, $S$. grandis could increase genet number by seeds, whereas $S$. krylovii could increase the number of ramets through changing the variability of vegetative growth, to adapt to disturbance and increase fitness. However, grazing had no significant effect on the ratios of ramet to genet number for both species. It is possible that the effect of grazing on the number of individuals and plant biomass was less than that of mowing (Wang, 1998). Thus, grazing and mowing had obviously different effects on the reproductive behaviors of $S$. grandis and S. krylovii.

Resource allocation to sexual reproduction is an important life-history characteristic of clonal plants (van Kleunen et al., 2002). In the long process of natural evolution, plants have formed a physiological 
mechanism that prioritizes the supply of resources and energy to reproductive organs (Pan, 2001). Once plants go into the sexual reproductive period, asexual reproduction and vegetative growth would be inhibited, and the inhibition effect is not eliminated until seeds mature (Yang et al., 2001; Yang and Zhang, 2006). In fact, disturbance can effectively influence the sexual reproductive process of plants. The present study indicated that compared to the unused treatment, grazing significantly decreased the ratio of vegetative to reproductive tiller biomass and the ratio of vegetative to reproductive tiller number of $S$. grandis. However, grazing significantly increased the ratio of vegetative to reproductive tiller number and the ratio of vegetative to reproductive tiller biomass of $S$. krylovii. The effect of mowing on these two ratios was also consistent with the effect of grazing for both species, and the differences were not significant. Seemingly, the results were not consistent with those of the reproductive behaviors described above, but in essence, they did not conflict. This was because that the ramet number of plants was the sum of vegetative (no-flowering) clone number and flowering clone number in the statistics of the ratio of ramet to genet number. However, in the statistics of the ratio of vegetative to flowering tiller number, the total ramet number was divided into vegetative tiller number and flowering tiller number, i.e. the latter distinguished the process of sexual reproduction of $S$. grandis and $S$. krylovii, and so led to the difference. Our results indicated that the effects of grazing and mowing on the flowering behaviors of $S$. grandis and S. krylovii were more complicated than had been assumed, and also reflected the strong reproductive plasticity of both species under disturbance.

Plant $\mathrm{C}$ and $\mathrm{N}$ metabolism is coordinated with each other on the plant $\mathrm{C}$ sources, energy, enzymes, the reducing power of common requirements, ATP and carbon skeletons (Sugiharto and Sugiyama, 1992). The degree of coordination directly affects plant growth rate, and hence the process of sexual reproduction of individual plants. We found that both S. grandis and S. krylovii had the highest C:N ratios for the mowing treatment, and $S$. krylovii also had a relatively higher $\mathrm{C}: \mathrm{N}$ ratio for the grazing treatment than for the unused treatment. Long-term mowing and grazing removed part or a large amount of plant biomass, and thus increased the $\mathrm{C}: \mathrm{N}$ ratio in plants, which promoted asexual reproduction and resulted in more vegetative tillers. However, biomass removal by mowing and grazing could lead to the increase of root to shoot biomass ratio of plants. We found logarithmic incremental relationships between the ratios of vegetative to reproductive tiller number and the ratios of root to shoot biomass for both S. grandis and S. krylovii, and this relationship was stronger in $S$. grandis than in $S$. krylovii. This implied that the increased root to shoot biomass ratio would promote the formation of vegetative tillers. Thus, for the mowing and grazing treatments, the higher $\mathrm{C}: \mathrm{N}$ ratios and the larger root to shoot biomass ratios of $S$. grandis and S. krylovii plants promoted their asexual reproduction and delayed their sexual reproductive process.

\section{Conclusion}

The mowing and grazing treatments could influence the carbon to nitrogen ratio of $S$. grandis and $S$. krylovii, while the carbon to nitrogen ratio was an important factor influencing plant root to shoot biomass ratio. Our results suggested that the root to shoot biomass ratio had a significantly positive effect on the vegetative to flowering tiller number ratio of $S$. grandis and S. krylovii. Our results revealed that the mowing treatment affected the ratio of ramet to genet number (i.e. the reproductive behavior) of S. krylovii,; while the grazing treatment notably affected the ratios of vegetative to reproductive tiller number and the ratios of vegetative to reproductive tiller biomass of $S$. grandis and S. krylovii (i.e. prevented them from entering the sexual reproductive process). Thus, the grazing and mowing treatments affected the reproductive behaviors of $S$. grandis and $S$. krylovii. The present study will be available to explain plant adaptive mechanisms to mowing and grazing disturbances, especially to verify plant adaptation to disturbance by means of reproductive behaviors.

\section{Acknowledgments}

This research was funded by the National Basic Research Program of China (2009CB421303, 2007CB106802). 


\section{References}

Adler P B, Raff D A, Lauenroth W K. 2001. The effect of grazing on the spatial heterogeneity of vegetation. Oecologia, 128: 465-479.

Aoyagi Y, Akimoto M. 2009. Reactive shifts in the pattern of resource allocation in three Lolium species with different levels of persistency under clipping disturbance. Grassland Science, 55: 181-186.

Bao S D. 2000. Analytical Methods of Soil and Agro-Chemistry. Beijing: Chinese Agriculture Press.

Begay B, Alexander H M, Questad E. 2011. Effect of mid-summer haying on growth and reproduction in prairie forbs. Transactions of the Kansas Academy of Science, 114: 108-114.

Brys R, Shefferson R P, Jacquemyn H. 2011. Impact of herbivory on flowering behaviour and life history trade-offs in a polycarpic herb: a 10-year experiment. Oecologia, 166: 293-303.

Chen X Y, Song Y C. 1997. Influence of flood disturbance on the regeneration of Cyclobalanopsis glauca populations. Journal of Tropical and Subtropical Botany, 5(1): 53-58.

De Jong T J, Goosen-de Roo L, Klinkhamer P G L. 1998. Is the threshold size for flowering in Cynoglossum officinale fixed or dependent on environment? New Phytologist, 138: 489-496.

Del Barrio J, Luis-Calabuig E, Tárrega R. 1999. Vegetative response of Arctostaphylos uva-ursi to experimental cutting and burning. Plant Ecology, 145: 191-195.

Denslow J S. 1980. Gap partitioning among tropical rainforest trees. Biotropica, 12: 47-55.

Franks S J, Sim S, Weis A E. 2007. Rapid evolution of flowering time by an annual plant in response to a climate fluctuation. Proceedings of the National Academy of Sciences of the United States of America, 104: 1278-1282.

Grime J P. 2001. Plant Strategies, Vegetation Process, and Ecosystem Properties. Chichester: John Wiley \& Sons Ltd.

Guo P, Zhang Z, Zhou C, et al. 2011. The regulation of reproductive growth of Stipa Grandis and Stipa Baicalensis in Hulunber steppe. Acta Agrestia Sinica, 19(3): 381-387.

Harper J L. 1977. Population Biology of Plants. London: Academic Press. He X D, Gao Y B, Liu H F. 2004. Amending of importance value and its application on classification of Leymus chinensiscommunities. Bulletin of Botanical Research, 24(4): 466-472.

Huhta A-P, Rautio P, Hellström K, et al. 2009. Tolerance of a perennial herb, Pimpinella saxifraga, to simulated flower herbivory and grazing: immediate repair of injury or postponed reproduction? Plant Ecology, 201: 599-609.

Inner Mongolia-Ningxia Integrated Survey Team. 1985. The Vegetation of Inner Mongolia. Beijing: Science Press.

Kioko J, Kiringe J W, Seno S O. 2012. Impacts of livestock grazing on a savanna grassland in Kenya. Journal of Arid Land, 4: 29-35.

Liu H F, Gao Y B, He X D, et al. 2004. Spatial variation of species composition and qualitative characteristics of the dominant species among different Leymus chinensis communities in mid-east Inner
Mongolia steppe. Grassland of China, 26(4): 1-10.

Liu S, Gao Y B, Chen S P, et al. 1999. A preliminary study on the clonal growth and adaptive strategy of Pennisetum centrasiaticum and Leymus secalinus. Journal of Desert Research, 19(1): 75-78.

Liu Z M, Jiang D M, Gao H Y, et al. 2003. Relationships between plant reproductive strategy and disturbance. Chinese Journal of Applied Ecology, 14(3): 418-422.

Liu Z M. 2010. Plant Regenerative Strategies in the Horqin Sand Land. Beijing: Meteorologic Press.

Mao W, Zhang T H, Li Y L, et al. 2012. Allometric response of perennial Pennisetum centrasiaticum Tzvel to nutrient and water limitation in the Horqin Sand Land of China. Journal of Arid Land, 4(2): 161-170.

McIntyre S, Lavorel S, Tremont R M. 1995. Plant life-history attributes: their relationship to disturbance response in herbaceous vegetation. Journal of Ecology, 83: 31-44.

Miao S L, Bazzaz F A. 1990. Responses to nutrient pulses of two colonizers requiring different disturbance frequencies. Ecology, 71: 2166-2178.

Mulder C P H, Ruess R W. 1998. Relationships between size, biomass allocation, reproduction, and survival in Triglochin palustris: implication for the effects of goose herbivory. Canadian Journal of Botany, 76: 2164-2176.

N'Guessan M, Hartnett D C. 2011. Differential responses to defoliation frequency in little bluestem (Schizachyrium scoparium) in tallgrass prairie: implications for herbivory tolerance and avoidance. Plant Ecology, 212: 1275-1285.

Obeso J R. 2002. The costs of reproduction in plants. New Phytologist, 155: $321-348$.

Pan R Z. 2001. Plant Physiology (4 ${ }^{\text {th }}$ ed.). Beijing: Higher Education Press.

Pausas J G. 1999. Response of plant functional types to changes in the fire regime in Mediterranean ecosystems: a simulation approach. Journal of vegetation Science, 10: 717-722.

Reisch C, Poschlod P. 2011. Morphology and phenology of Scabiosa columbaria from mown and grazed habitats-Results of a simulation experiment. Flora, 206: 887-891.

Reznick D. 1985. Cost of reproduction: an evaluation of the empirical evidence. Oikos, 44: 257-267.

Song Y C. 2001. Vegetation Ecology. Shanghai: Huadong Normal University Press.

Stearns S C. 1992. The Evolution of Life Histories. London: Oxford University Press.

Sugiharto B, Sugiyama T. 1992. Effects of nitrate and ammonium on gene expression of phosphoenolpyruvate carboxylase and nitrogen metabolism in maize leaf tissue during recovery from nitrogen stress. Plant Physiology, 98: 1403-1408.

Taisma M A, Herrera A. 1998. A relationship between fecundity, survival, and the operation of crassulacean acid metabolism in Talinum traiangulare. Canadian Journal of Botany, 76: 1908-1915. 
Van Kleunen M, Fischer M, Schemid B. 2002. Experimental life-history evolution: selection on the allocation to sexual reproduction and its plasticity in a clonal plant. Evolution, 56: 2168-2177.

Van Tienderen P H, van der Toorn J. 1991. Genetic differentiation between populations of Plantago lanceolata. I. Local adaptation in three contrasting habitats. Journal of Ecology, 79: 27-42.

Wang R Z. 1998. A study on the effects of grazing and mowing disturbances in Leymus chinensis grassland in songnen plain. Acta Ecologica Sinica, 18(2): 210-213.

Weiher E, van der Werf A, Thompson K, et al. 1999. Challenging Theophrastus: a common core list of plant traits for functional ecol- ogy. Journal of Vegetation Science, 10: 609-620.

Wilkins P W. 2002. Dry matter yield, herbage quality and persistency of equivalent populations of perennial ryegrass with and without reduced flowering. Plant Breed, 121: 425-428

Yang Y F, Zheng H Y, Li J D. 2001. The effects of grazing on age structure in clonal populations of Agropyron michnoi. Acta Phytoecologica Sinica, 25(1): 71-75.

Yang Y F, Zhang B T. 2006. Phenotype plasticity and regulations of reproductive modules on Glycyrrhiza uralensis population in meadow habitat in Songnen Plain, China. Acta Prataculturae Sinica, 15(2): 14-20. 